\title{
Potential Protective Effects of Bioactive Constituents from Chinese Propolis against Acute Oxidative Stress Induced by Hydrogen Peroxide in Cardiac H9c2 Cells
}

\author{
Liping Sun, ${ }^{1,2}$ Kai Wang, ${ }^{1,3}$ Xiang Xu, ${ }^{1,2}$ Miaomiao Ge, ${ }^{1,2}$ Yifan Chen, ${ }^{3}$ and Fuliang $\mathrm{Hu}^{3}$ \\ ${ }^{1}$ Institute of Apicultural Research, Chinese Academy of Agricultural Sciences, Beijing 100093, China \\ ${ }^{2}$ National Research Center of Bee Product Processing, Ministry of Agriculture, Beijing 100093, China \\ ${ }^{3}$ College of Animal Sciences, Zhejiang University, Hangzhou 310058, China \\ Correspondence should be addressed to Liping Sun; caasun@126.com
}

Received 12 December 2016; Accepted 2 February 2017; Published 27 February 2017

Academic Editor: Salvatore Chirumbolo

Copyright (C) 2017 Liping Sun et al. This is an open access article distributed under the Creative Commons Attribution License, which permits unrestricted use, distribution, and reproduction in any medium, provided the original work is properly cited.

\begin{abstract}
Chinese propolis (CP) is known as a health food but its beneficial effects in protecting cardiomyocytes remain elusive. Here, we investigated the effects of $\mathrm{CP}$ and its active compounds on hydrogen peroxide $\left(\mathrm{H}_{2} \mathrm{O}_{2}\right)$ induced rats cardiomyocytes (H9c2) oxidative injury. Cell viability decreases induced by $\mathrm{H}_{2} \mathrm{O}_{2}$ were mitigated by different $\mathrm{CP}$ extracts using various solvents. From these active fractions, six active compounds were separated and identified. Among tested isolated compound, the cytoprotective activities of three caffeates, caffeic acid phenethyl ester (CAPE), benzyl caffeate (BZC), and cinnamyl caffeate (CNC), exerted stronger effects than chrysin, pinobanksin, and 3,4-dimethoxycinnamic acid (DMCA). These three caffeates also increased H9c2 cellular antioxidant potential, decreased intracellular calcium ion $\left(\left[\mathrm{Ca}^{2+}\right]_{\mathrm{i}}\right)$ level, and prevented cell apoptosis. Overall, the cardiovascular protective effects of the CP might be attributed to its caffeates constituents (CAPE, BZC, and CNC) and provide evidence for its usage in complementary and alternative medicine.
\end{abstract}

\section{Introduction}

Cardiovascular disease (CV) is responsible for $30 \%$ of deaths worldwide, surpassed other diseases, and is projected to account for 25 million deaths annually by 2030 [1]. The cost of CV estimated U.S. $\$ 863$ billion (in 2010) [2]. Myocardial ischemia (MI), commonly known as angina, is one of the major clinical indications of CV and mainly caused by intraluminal coronary thrombosis and ruptured atherosclerotic plaque [3]. Ischemic damages to the cardiac cells are known to be related to reactive oxygen species (ROS) produced during tissue ischemia, which will lead to cardiomyocytes' oxidative stress and further lead to apoptotic cell death [4]. Now one major interesting area is to understand and to prevent cardiac cell death associated with oxidative stress, and several antioxidants have been shown with promising therapeutic effects [5].

Chinese propolis $(\mathrm{CP})$ is an important hive product collected by honeybees (Apis mellifera) from buds of plants
[6]. CP is widely used as a natural antioxidant and is as a well-known functional food for its biological activities, like anti-inflammatory, antimicrobial, liver detoxifying, and cardioprotective effects $[7,8]$. Moreover, the antioxidant basis of $\mathrm{CP}$ might attribute to its abundant polyphenolic compounds, mainly flavonids, quercetin, chrysin, kaempferol, pinocembrin, or phenolic acids and its esters, including caffeic acid and CAPE, $p$-coumaric acid [8]. Recently, cardioprotective effect of propolis extract has been investigated both in vitro and in vivo [9]. Although the mechanisms of action beyond these polyphenolic compounds from propolis are not welldefined, it is still convincible that some of their protective effect by propolis can be attributed to direct scavenging properties of these polyphenolic compounds in CP [10].

The study of the material basis and mechanism of natural medicine including propolis always becomes a critical issue for its potential clinical application and modern medicine development [11]. However, mechanisms underlying the cardioprotective effects of $\mathrm{CP}$ and its bioactive constituent 
basis are still lacking. In the present study, we aim to investigate the protective effects of $\mathrm{CP}$ against $\mathrm{H}_{2} \mathrm{O}_{2}$ induced rat cardiac $\mathrm{H} 9 \mathrm{c} 2$ injury and to explore the potential bioactive compounds of CP.

\section{Material and Methods}

2.1. Regents. HPLC grade methanol was purchased from Merck (Darmstadt, Germany) analytical grade solvents were purchased from Beijing Chemical Works (Beijing, China). Quercetin, Fura-2/AM probe, Annexin V-FITC/PI cell apoptosis kit and the standards used in the chromatography analysis were purchased from Sigma (St. Louis, MO, USA). Other chemicals were of analytical grade and purchased from Sangon Biotechnology (Shanghai, China).

2.2. Cell Culture and Cell Viability Assay. Rat H9c2 cardiomyocyte cell line was obtained from ATCC (American Type Culture Collection). Cells were cultured using high glucose Dulbecco's modified Eagle's medium with $4.0 \mathrm{mM} \mathrm{L-}$ glutamine (Thermo Scientific) supplemented with $1 \%$ penicillin/streptomycin (Solarbio, Beijing, China) and 10\% fetal bovine serum (Gibco, Carlsbad, CA, USA). Cells were split when a confluence of $\sim 70 \%$ was achieved using trypsinEDTA (Solarbio, Beijing, China) and subcultured at a ratio of $1: 3$. H9c2 cardiomyocytes were seeded at a density of $1.2 \times$ $10^{6}$ cells/well.

$\mathrm{H}_{2} \mathrm{O}_{2}(30 \%, 3 \mu \mathrm{L})$ was diluted by cell culture medium (high glucose DMEM, $3 \mathrm{~mL}$ ) to obtain $10 \mathrm{mM}$ stock and further diluted to specific working solutions. The H9c2 cells were cultured in DMEM without FBS for $12 \mathrm{~h}$ and then treated with various concentrations of $\mathrm{H}_{2} \mathrm{O}_{2}$ for different periods. Cell viability assay was then performed using a CCK8 kit. Cellular morphology was observed under an inverted microscope.

Cell viability assay was performed using CCK-8 kit (Solarbio, Beijing, China) according to the manufacture's instruction. Then the optical density (OD) at $450 \mathrm{~nm}$ for each well was measured by a microplate reader (Synergy HT, BioTek Instruments, Winooski, VT). Cell viability was also confirmed by trypan blue exclusion and microscopy examination during the following experiments.

\subsection{CP Active Compounds Separation, \\ Determination, and Selection}

2.3.1. CP Sample Preparation. CP was collected from Shandong, China, and the botanical origin was poplar (Populus $s p$.). A voucher specimen was deposited at Institute of Apicultural Research, Chinese Academy of Agricultural Sciences, China. The propolis stored at $-20^{\circ} \mathrm{C}$ was grinded into powder with a grinder and extracted by $40 \%$ ethanol at $30^{\circ} \mathrm{C}$, and then the propolis sample was filtered and concentrated under vacuum using a rotary evaporator. The residues were washed and dried to obtain $40 \%$ ethanol upper fraction (40EU), and the supernatants were rotated and dried to obtain $40 \%$ propolis extracts (40EL). The 70\% ethanol and 95\% ethanol were further used to extract from the residues to get $70 \%$ ethanol extracted propolis (70E) and 95\% ethanol extracted propolis (95E).

2.3.2. Fractional Extraction of $C P$. Propolis sample was mixed by petroleum ether, ethyl acetate, acetone, and methyl alcohol (the proportion of solid to liquid is $1: 10$ ). After standing delaminating and evaporation of the solvent, paste-like extraction was obtained. TLC (thin-layer chromatography) condition as followed, chloroform : methanol: formic acid $=$ $8.8: 0.5: 1.0$. ferric trichloride $(2 \%)$ as the chromogenic agent.

\subsection{Separation, Purification, and Determination of Propolis Extracts}

2.4.1. Column Chromatography. Column was packed with 200-300 mesh silica gel. After eluting with dichloromethaneacetone system in normal pressure, six components were obtained. Column chromatography was performed by SiliaSphere C18 chromatography column (packed with 300400 mesh silica gel), eluted with chloroform-methanol, dichloromethane-methanol, petroleum ether-ethyl acetate, and methanol- $\mathrm{H}_{2} \mathrm{O}$ system with a solvent flow rate of $10 \mathrm{~mL} / \mathrm{min}$ in medium-pressure.

2.4.2. High-Performance Liquid Chromatography (HPLC) Analysis. HPLC analyses were carried out on an Agilent HPLC system. The separation was performed on Agilent C18 column $(250 \mathrm{~mm} \times 4.6 \mathrm{~mm}, 5 \mu \mathrm{m})$ with a flow rate of $1.0 \mathrm{~mL} / \mathrm{min}$ at $40^{\circ} \mathrm{C}$, eluted with methanol- $\mathrm{H}_{2} \mathrm{O}$ system. The preparative HPLC was equipped with an Agilent SB C18 column $(150 \mathrm{~mm} \times 21.2 \mathrm{~mm}, 5 \mu \mathrm{m})$ with a flow rate of $20 \mathrm{~mL} / \mathrm{min}$ at $40^{\circ} \mathrm{C}$.

2.4.3. LC-MS Determination. An Agilent SB C18 column $(2.1 \mathrm{~mm} \times 50 \mathrm{~mm}, 1.8 \mu \mathrm{m})$ was used for the separation at a flow rate of $0.2 \mathrm{~mL} / \mathrm{min}$. The mobile phase comprised aqueous $60 \%$ methanol. The column was maintained at $40^{\circ} \mathrm{C}$. Mass spectrometer operated in negative and positive full-scan mode in the range $100-1000 \mathrm{Da}$. The capillary voltage set to $4.0 \mathrm{kV}$ and the desolvation temperature was $350^{\circ} \mathrm{C}$. The cone gas flow was set at $6 \mathrm{~L} / \mathrm{h}$, while the desolvation gas flow was set to $9 \mathrm{~L} / \mathrm{h}$, and the collision energy at $20 \mathrm{~V}$.

\subsection{Cellular Antioxidant Activity Determination}

2.5.1. Measurement of Cellular SOD Activity. The H9c2 cells were seeded into 24 -well plates at a density of $1 \times 10^{5}$ cells $/ \mathrm{mL}$. Then the DMEM of propolis treated group was removed and $1 \%$ Triton $\times 100$ was added into cells and incubated for $30 \mathrm{~min}$. After this incubation, cells were collected by centrifugation at $2500 \mathrm{rpm}$ for $10 \mathrm{~min}$. The supernatants separated were used $100 \mathrm{ul}$ for measurement of SOD activities according to the manufacturer's instructions (Jiancheng Bioengineering Institute, Nanjing, China).

2.5.2. Measurement of MDA Activity. Cell culture and treatment methods were as described. We collected $150 \mu \mathrm{L}$ supernatants of cell lysate for MDA levels measurement according to the manufacturer's instructions (Jiancheng Bioengineering Institute). 
2.5.3. Measurement of GSH-Px Activity. Supernatants $(200 \mu \mathrm{L})$ were used for measurement of GSH-Px content according to the manufacturer's instructions (Jiancheng Bioengineering Institute).

2.6. Determination of Intracellular Calcium Ion $\left(\left[\mathrm{Ca}^{2+}\right]_{i}\right)$. $\mathrm{H} 9 \mathrm{c} 2$ cells were digested and seeded into culture plate $\left(10^{5}\right.$ cells $/ \mathrm{mL}$ ) at $37^{\circ} \mathrm{C}$ in a $5 \% \mathrm{CO}_{2}$ atmosphere. The cell medium was discarded and washed cells with HBSS buffer solution 3 times, then added Fura-2/AM and incubated $45 \mathrm{~min}$ at $37^{\circ} \mathrm{C}$ in the dark. After the incubation, the cells were washed 2-3 times with HBSS solution and then $2 \mathrm{~mL}$ EBSS buffer solution was loaded. Fura-2 fluorescence was excited alternately at 340 and $380 \mathrm{~nm}$ and the $340 / 380$ ratio was obtained. Values for $R \min , F 380$ max, F $380 \mathrm{~min}, R \max$ and $K d$ were obtained using the Fura-2 Calcium Imaging Calibration Kit (Molecular Probes).

2.7. Cell Apoptosis Analysis Using Flow Cytometry. Cardiomyocytes were labeled with Annexin V-FITC and PI, and apoptosis rate was measured by flow cytometry using a Cell Llab Quanta ${ }^{\mathrm{TM}}$ SC flow cytometer (Beckman Coulter Inc., Miami, FL). H9c2 cells were digested and seeded into culture plate to a density of $5 \times 10^{5}$ cells $/ \mathrm{mL}$ at $37^{\circ} \mathrm{C}, 5 \% \mathrm{CO}_{2}$ before the experiment. Cells were then centrifuged at $1000 \mathrm{rpm}$ 5 min and washed 2 times with PBS and $500 \mu \mathrm{L}$ of conjugation buffer was added to resuspend the cells. Then $5 \mu \mathrm{L}$ Annexin $\mathrm{V}$-FITC and $10 \mu \mathrm{L}$ PI were loaded and reacted for $10 \mathrm{~min}$ before FCM analysis.

2.8. Statistical Analysis. All experiments were performed in triplicate, and each experiment was repeated at least three times. All values are presented as mean $\pm \mathrm{SD}$. The data were analyzed by one-way analysis of variance followed by post hoc Dunnett's $t$-test for multiple comparisons. Values of $P<0.05$ were considered to be statistically significant.

\section{Results and Discussion}

3.1. Oxidative Damage Model Establishment in H9c2 Cardiomyocytes. Myocardial damage is largely due to the generation of ROS. ROS-induced effects of ischemia-reperfusion and myocardial dysfunction could be alleviated by treating the tissue with antioxidants or blocking signaling-related ROS generation. Based on this concept, several practices have been performed to evaluate the effects of antioxidants, including propolis, on myocardial injuries in animals and patients $[12,13]$.

We challenged $\mathrm{H} 9 \mathrm{c} 2$ cardiomyocytes with various concentrations of $\mathrm{H}_{2} \mathrm{O}_{2}(0-900 \mathrm{mM})$ for different time periods $(0$ to $6 \mathrm{~h})$ to induce in vitro oxidative damage. As shown in Figure 1(a), H9c2 cell viability decreased significantly in a time- and dose-dependent manner after $\mathrm{H}_{2} \mathrm{O}_{2}$ treatment. Six hours after $\mathrm{H}_{2} \mathrm{O}_{2}$ challenge, more than $50 \%$ cell viability losses were observed in 700 and $900 \mathrm{mM} \mathrm{H}_{2} \mathrm{O}_{2} \mathrm{H} 9 \mathrm{c} 2$ cells $(P<0.01$ compared with control cells). In parallel, damaged cell morphology was observed using an inverted microscope, shown as broken cellular membranes, swelling, and vacuole degeneration in $700 \mathrm{mM} \mathrm{H}_{2} \mathrm{O}_{2}$ treated $\mathrm{H} 9 \mathrm{c} 2$ cells (Figure 1(b)), which were quite similar to several previous studies using H9c2 cells [14].
Propolis has abundant polyphenolic constituents, like flavonoids and phenolic acids [15]. These constituents are known with good antioxidant, iron-chelating, and carbonyl reductase-inhibitory effects, which act as new protective compounds against cardiotoxicity [16-18]. It has been reported that quercetin, an important flavonoid abundantly found in fruits, vegetables, wine, and tea (also found in CP $[10,19])$, exerts protective effects against $\mathrm{H}_{2} \mathrm{O}_{2}$ cardiotoxicity in $\mathrm{H} 9 \mathrm{c} 2$ cardiomyocytes $[20,21]$. We used $5 \mu \mathrm{M}$ quercetin as a positive control in this study, which rescued cell viability from $53.9 \%$ to $86.0 \%$ in $700 \mathrm{mM} \mathrm{H}_{2} \mathrm{O}_{2}$ treated $\mathrm{H} 9 \mathrm{c} 2$ cells for $4 \mathrm{~h}$ (Figure $1(\mathrm{c})$ ), whereas $900 \mathrm{mM} \mathrm{H}_{2} \mathrm{O}_{2}$ insult with $5 \mu \mathrm{M}$ quercetin pretreatment can only rescue $\mathrm{H} 9 \mathrm{c} 2$ cell viability to $60 \%$, suggesting that oxidative damage induced by this concentration $\mathrm{H}_{2} \mathrm{O}_{2}$ was irreversible. Therefore, in our system, $700 \mu \mathrm{M} \mathrm{H}_{2} \mathrm{O}_{2}$ challenge for $4 \mathrm{~h}$ was chosen in the subsequent experiments as an oxidative damage model.

\section{2. $\mathrm{CP}$ Extracts and Its Fractions Inhibit $\mathrm{H}_{2} \mathrm{O}_{2}$-Induced Cell} Death in $\mathrm{H} 9 \mathrm{c} 2$ Cardiomyocytes. It has been known that different solvents will affect yield of bioactive constituents, like flavonoids or phenolic acids [22]. To find active cardioprotective fractions from $\mathrm{CP}$, different ethanol CP extracts were screened in $\mathrm{H}_{2} \mathrm{O}_{2}$ challenged $\mathrm{H} 9 \mathrm{c} 2$ cells. As shown in Figure 2(a), among all CP fractions tested, 70\% ethanol fraction (70E) showed strongest protective effects against $\mathrm{H}_{2} \mathrm{O}_{2}$ challenge (with a cell viability of $51.3 \pm 1.0 \%$ ), in which the cell viability significantly increased to $75.8 \pm 0.2 \%$ $(P<0.01)$. Nevertheless, both $40 \%$ ethanol upper fraction and lower fraction (40EU and 40EL) showed less potent protective effects against $\mathrm{H} 9 \mathrm{c} 2$ cell viability decreases, which were significant from $70 \mathrm{E}$ fraction. Since the protective effects of $90 \%$ ethanol fraction (90E) were quite similar to $70 \mathrm{E}$ fraction, we merged them for the following fractionation.

Further, merged 70E and 90E fractions were sequentially fractionated into five subextracts explicitly, namely, petroleum ether (PE), dichloromethane (DCM), ethyl acetate (EtOAc), and acetone (thin layer chromatography, TLC, profile of these fractions was shown in Supplemental Figure 1 in Supplementary Material available online at https://doi.org/10.1155/ 2017/7074147). As shown in Figure 2(b), EtOAc subfraction and acetone subfraction showed most effective protective effects and kept for next fractionation.

Subsequently, combined EtOAc and acetone subfractions were separated over a silica gel column and six subfractions were obtained (TLC profile was shown in Supplemental Figure 2). As shown in Figure 2(c), the cytoprotective effect by fraction 3 was the strongest among all tested fractions, which was comparable to the quercetin positive control. Based on these results, we chosen this fraction for the active compound isolation and structure elucidation.

3.3. Active Compounds Isolation and Characterization of $C P$ Extracts Responsible for Its Cardioprotective Activities. Fraction 3 from EtOAc and acetone sub-fraction was repeatedly separated by silica gel column chromatography, purified by reverse phase HPLC (Figure 3(a)), six known compounds, which is (1) 3,4-dimethoxycinnamic acid (DMCA) [23], (2) pinobanksin [24], (3) benzyl caffeate (BZC) [25], (4) chrysin 


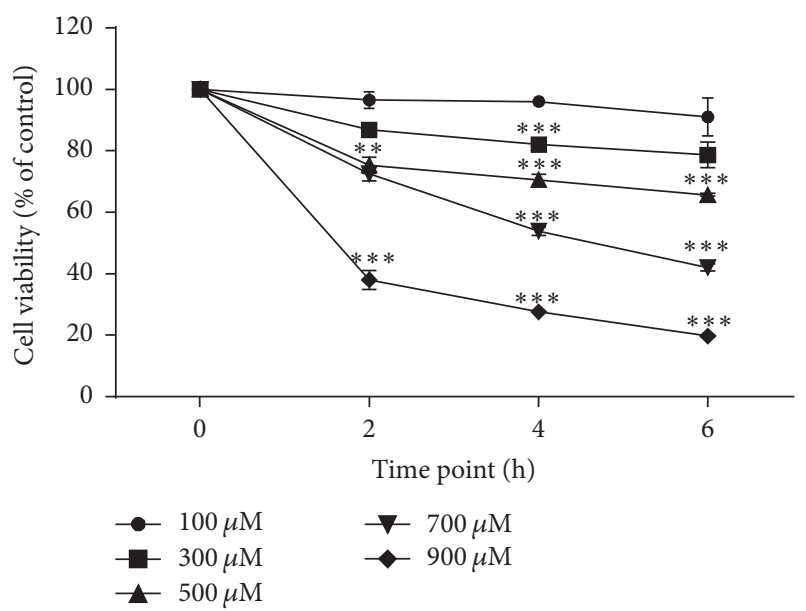

(a)
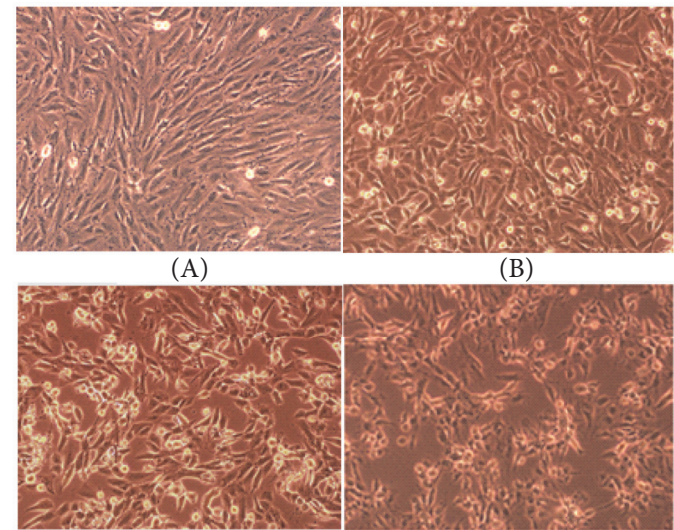

(C)

(D)

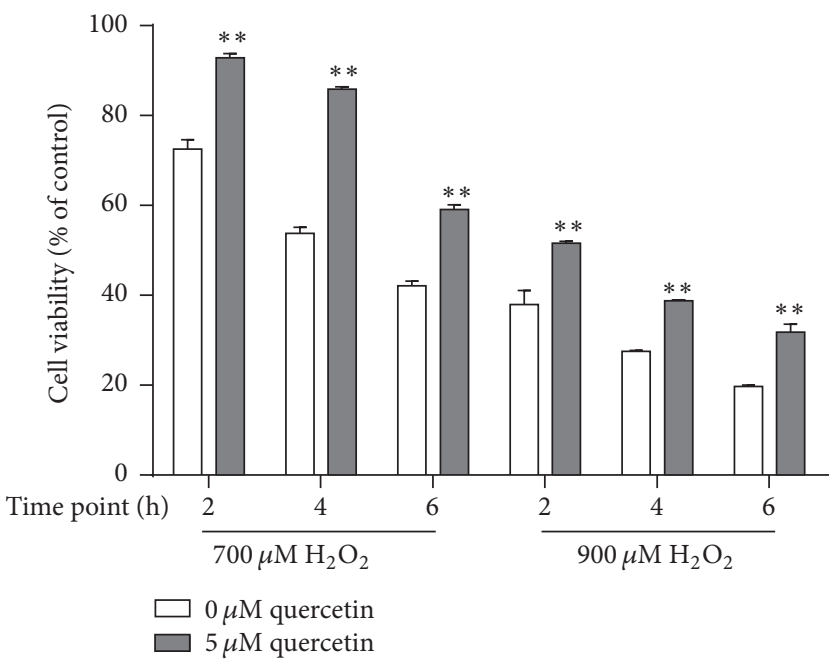

(b)

(c)

FIGURE 1: Oxidative damage model establishment in $\mathrm{H} 9 \mathrm{c} 2$ cardiomyocytes. (a) $\mathrm{H} 9 \mathrm{c} 2$ cells were treated with various concentrations of $\mathrm{H}_{2} \mathrm{O}_{2}$ $(100 \mu \mathrm{M}, 300 \mu \mathrm{M}, 500 \mu \mathrm{M}, 700 \mu \mathrm{M}$, and $900 \mu \mathrm{M})$ for different time periods (2, 4, and $6 \mathrm{~h})$. (b) $\mathrm{H} 9 \mathrm{c} 2$ cell morphology from $700 \mu \mathrm{M} \mathrm{H}_{2} \mathrm{O}_{2}$ stimulation for $0 \mathrm{~h}(\mathrm{~A}), 2 \mathrm{~h}(\mathrm{~B}), 4 \mathrm{~h}(\mathrm{C})$, and $6 \mathrm{~h}(\mathrm{D})$. (c) Comparisons of cell survival rates between quercetin treatment group and oxidative injury group. $\mathrm{H} 9 \mathrm{c} 2$ cardiomyocytes were pretreated with $5 \mu \mathrm{M}$ quercetin or not for $12 \mathrm{~h}$ and then challenged with 700 or $900 \mu \mathrm{M} \mathrm{H} \mathrm{H}_{2}$ for $2 \mathrm{~h}, 4 \mathrm{~h}$, and 6 h. ${ }^{* *} \mathrm{P}<0.01$ and ${ }^{* * *} \mathrm{P}<0.001$ compared with $\mathrm{H}_{2} \mathrm{O}_{2}$ controls.

[23], (5) caffeic acid phenethyl ester (CAPE) $[23,26]$ and (6) cinnamyl caffeate $(\mathrm{CNC})[23,27]$.

Next, we examined different concentrations of these isolated active compounds on $\mathrm{H}_{2} \mathrm{O}_{2}$ induced $\mathrm{H} 9 \mathrm{c} 2$ cell viability decreases. Compared to oxidative damage control group, $10 \mu \mathrm{M}$ of tested compounds showed significant protective effects $(P<0.01)$. These results provided further evidence which previously stated that chrysin can alleviate acute cardiotoxicity in rats [28].

Caffeic acid esters, major active compounds widely found in propolis, were reported to have a wide range of biological effects, which were also quite similar to propolis, like antitumour, antioxidant, and anti-inflammatory activities [13]. We noticed that three major caffeate derivatives, BZC, CAPE, and $\mathrm{CNC}$, exerted stronger protective effects than the remaining three polyphenolic acids (DMCA, chrysin, and pinobanksin) in damaged H9c2 cells (Figure 3(b)). These caffeate derivatives were further investigated regarding their cardiac cell protective mechanisms.

3.4. Caffeate Derivatives in CP Increased Cellular Antioxidant Activities in H9c2 Cardiomyocytes. Oxidative stress was considered as a major challenge during the cardiac ischemic damages, which can be reflected by measurement of the products of free-radical attack on biological substrates (MDA) as well as intracellular and extracellular anti-oxidant 


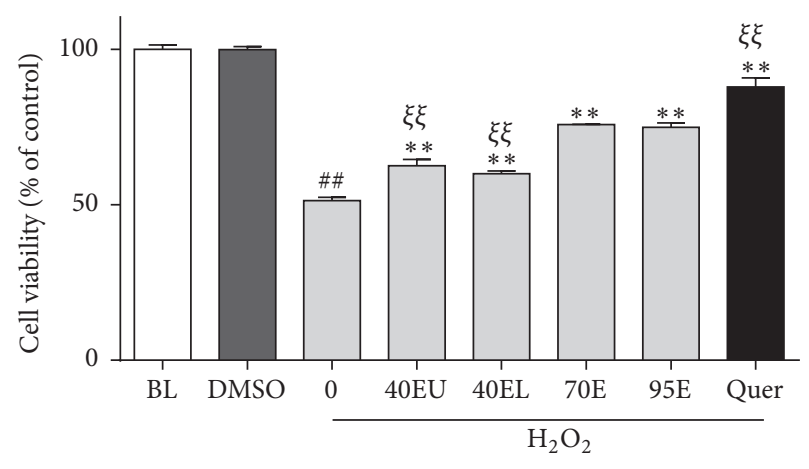

(a)

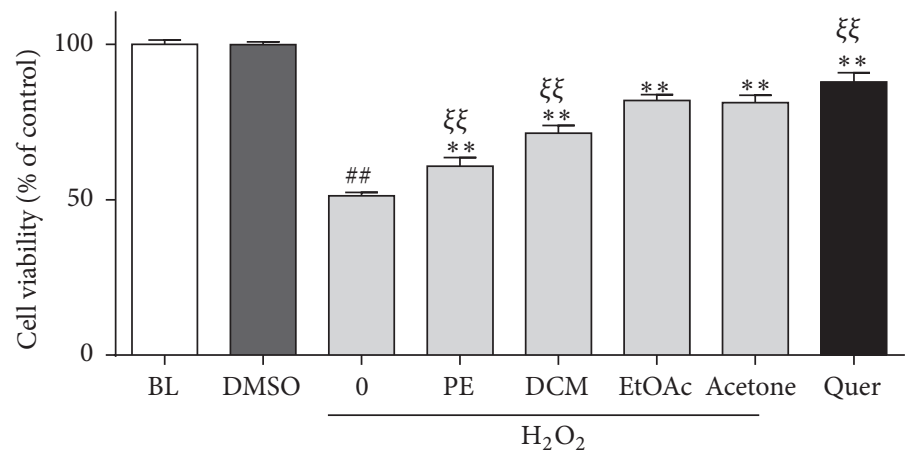

(b)

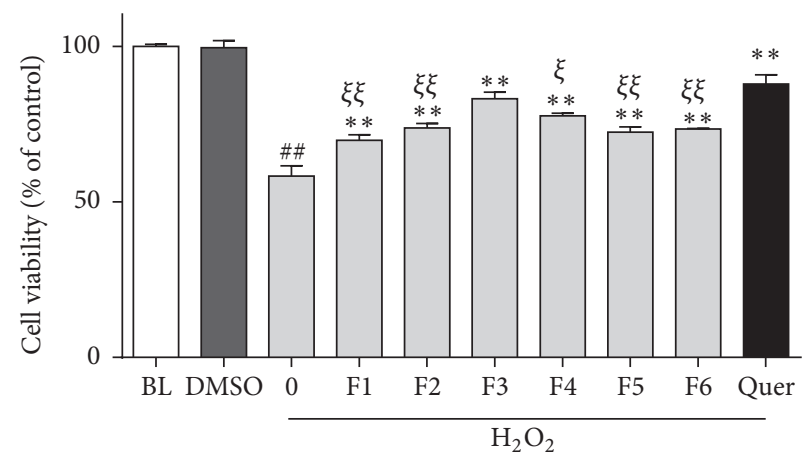

(c)

FIGURE 2: (a) Effects of different alcoholic extracts of CP on H9c2 cardiomyocytes cell viability decreases induced by $\mathrm{H}_{2} \mathrm{O}_{2}$ (700 $\mu \mathrm{M}$ for 6 h). $\mathrm{H} 9 \mathrm{c} 2$ cardiomyocytes were pretreated with $20 \mu \mathrm{g} / \mathrm{mL}$ alcoholic extracts of propolis, that is, $70 \%$ ethanol fraction $(70 \mathrm{E}), 95 \%$ ethanol fraction (95E), $40 \%$ ethanol upper fraction (40EU), and $40 \%$ ethanol lower fraction (40EL). Quercetin $(5 \mu \mathrm{M})$ served as a positive control. ${ }^{* *} P<0.01$ versus oxidative injury group, ${ }^{\# \#} P<0.01$ versus control group, and ${ }^{\xi \xi} \mathrm{P}<0.01$ versus $70 \mathrm{E}$ group. (b) Effects of different fractions from CP using different solvents on $\mathrm{H} 9 \mathrm{c} 2$ cardiomyocytes cell viability decreases induced by $\mathrm{H}_{2} \mathrm{O}_{2}(700 \mu \mathrm{M}$ for $6 \mathrm{~h})$, that is, petroleum ether (PE), dichloromethane (DCM), ethyl acetate (EtOAc), and acetone fractions. Quercetin $(5 \mu \mathrm{M})$ served as a positive control. ${ }^{* *} P<0.01$ versus oxidative injury group, ${ }^{\# \#} P<0.01$ versus control group, and ${ }^{\xi \xi} P<0.01$ versus EtOAc group. (c) Effects of different subfractions (fractions 1 to 7) from CP EtOAc/acetone fraction on $\mathrm{H} 9 \mathrm{c} 2$ cardiomyocytes cell viability decreases induced by $\mathrm{H}_{2} \mathrm{O}_{2}(700 \mu \mathrm{M}$ for $6 \mathrm{~h}){ }^{* *} P<0.01$ versus oxidative injury group, ${ }^{\# \#} P<0.01$ versus control group, and ${ }^{\xi \xi} P<0.01,{ }^{\xi} P<0.05$ versus fraction 3 group.

capacity (SOD and GSH-Px). MDA is recognized as an indirect oxidative stress marker of cellular injury due to itself is one of the end products of lipid peroxidation [29]. SOD and GSH-Px are known as main endogenous antioxidant enzymes which can neutralize free radicals and protect cells from ROS insults [30]. In our hands, we found that $\mathrm{H} 9 \mathrm{c} 2$ cells exposed to $\mathrm{H}_{2} \mathrm{O}_{2}$ showed a significant increase in MDA levels (Figure 4(a)), which was ameliorated by pretreatment with 5 and $10 \mu \mathrm{M}$ caffeate derivatives (BZC, CAPE, and $\mathrm{CNC}$ ). In addition, activity of endogenous antioxidative enzymes, SOD (Figure 4(b)) and GSH-Px (Figure 4(c)), was significantly decreased by $\mathrm{H}_{2} \mathrm{O}_{2}$ exposure. However, pretreatments of BZC, CAPE and CNC effectively mount up SOD and GSH-Px dose-dependently, suggesting that these caffeate derivatives isolated from $\mathrm{CP}$ might reduce oxidative damage by enhancing the endogenous antioxidant capacity in H9c2 cardiomyocytes.

3.5. Caffeate Derivatives in CP Decreased the $\mathrm{H}_{2} \mathrm{O}_{2}$ Induced Elevation of $\left[\mathrm{Ca}^{2+}\right]_{i}$ and Inhibited Cell Apoptosis in $\mathrm{H} 9 \mathrm{C} 2 \mathrm{Car}$ diomyocytes. Calcium is frequently played in the oxidative stress induced cellular injury $[31,32]$. In order to further investigate the protective effects by CP active constituents, $\left[\mathrm{Ca}^{2+}\right]_{i}$ were determined in $\mathrm{H} 9 \mathrm{c} 2$ cells (Figure 5(a)). All of three caffeate derivatives $(5$ and $10 \mu \mathrm{M})$ pretreatment significantly brought back myocardial ionizable calcium to near positive quercetin control. These data are consistent with a previous study in human endothelial cells (HUVEC) that cytosolic $\left[\mathrm{Ca}^{2+}\right]_{\mathrm{i}}$ were also increased by CAPE [33]. Also, these results provided novel evidence for the other two caffeates, which have promising potential in regulating cellular calcium homeostasis [34].

Myocardial ischemic damages can be affected by apoptosis through at least three potential mechanisms: (1) reducing myocardial cell numbers, which will directly decrease the heart pumping function; (2) damaging the heart's conduction function; and (3) initiating myocardial remodeling and inducing other cardiac pathological changes [29, 35]. For quantitative analyses of myocardial apoptosis, flow cytometry (FCM) with Annexin V-FITC and PI staining was used to detect $\mathrm{H} 9 \mathrm{c} 2$ cellular apoptosis. Compared to $\mathrm{H}_{2} \mathrm{O}_{2}$ damage group (16.8\%-18.8\% apoptotic cell rates), significant 


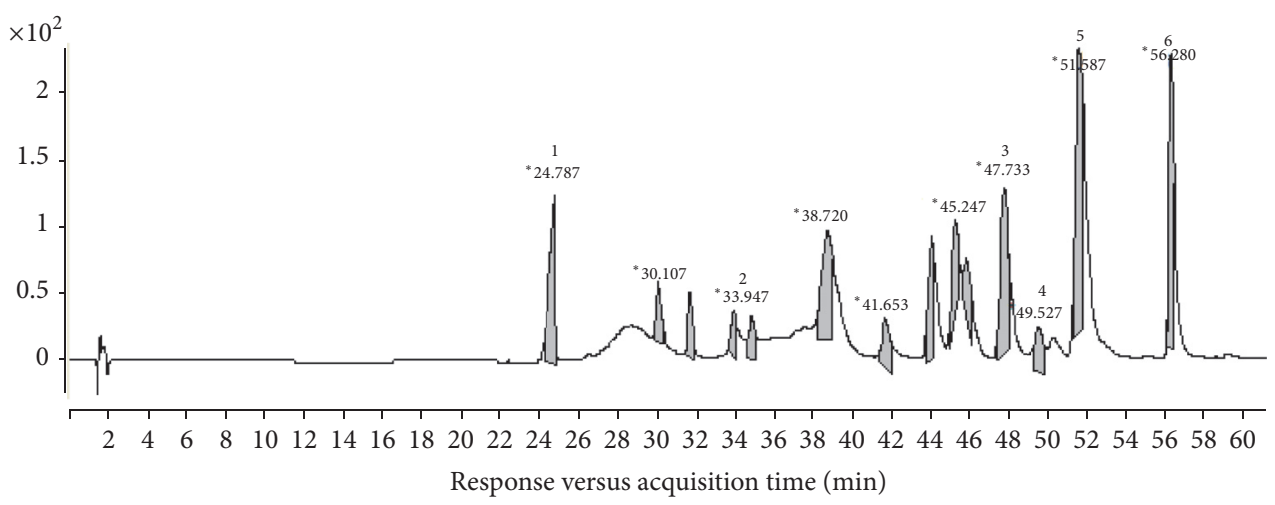

(a)

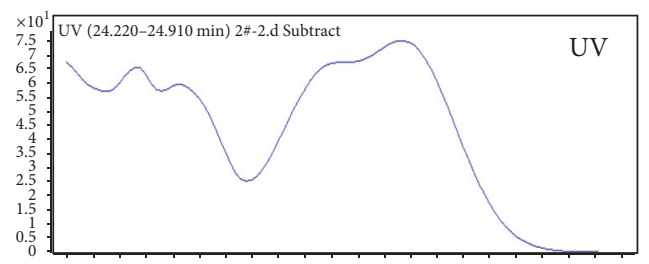

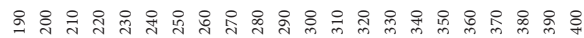
mAU versus wavelength $(\mathrm{nm})$

(b)

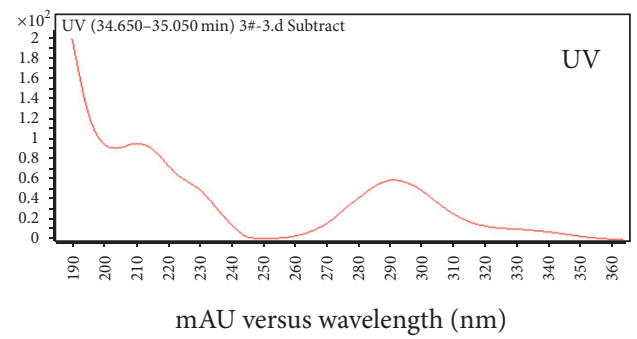

(c)

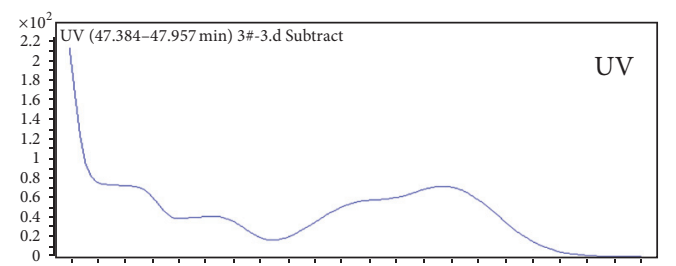

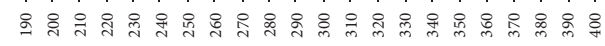
mAU versus wavelength (nm)

(d)

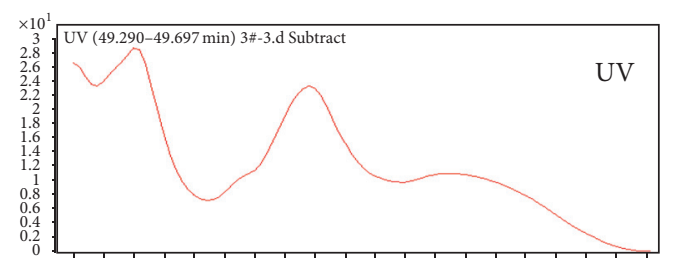

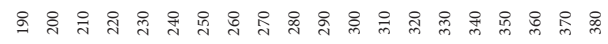
$\mathrm{mAU}$ versus wavelength $(\mathrm{nm})$

)
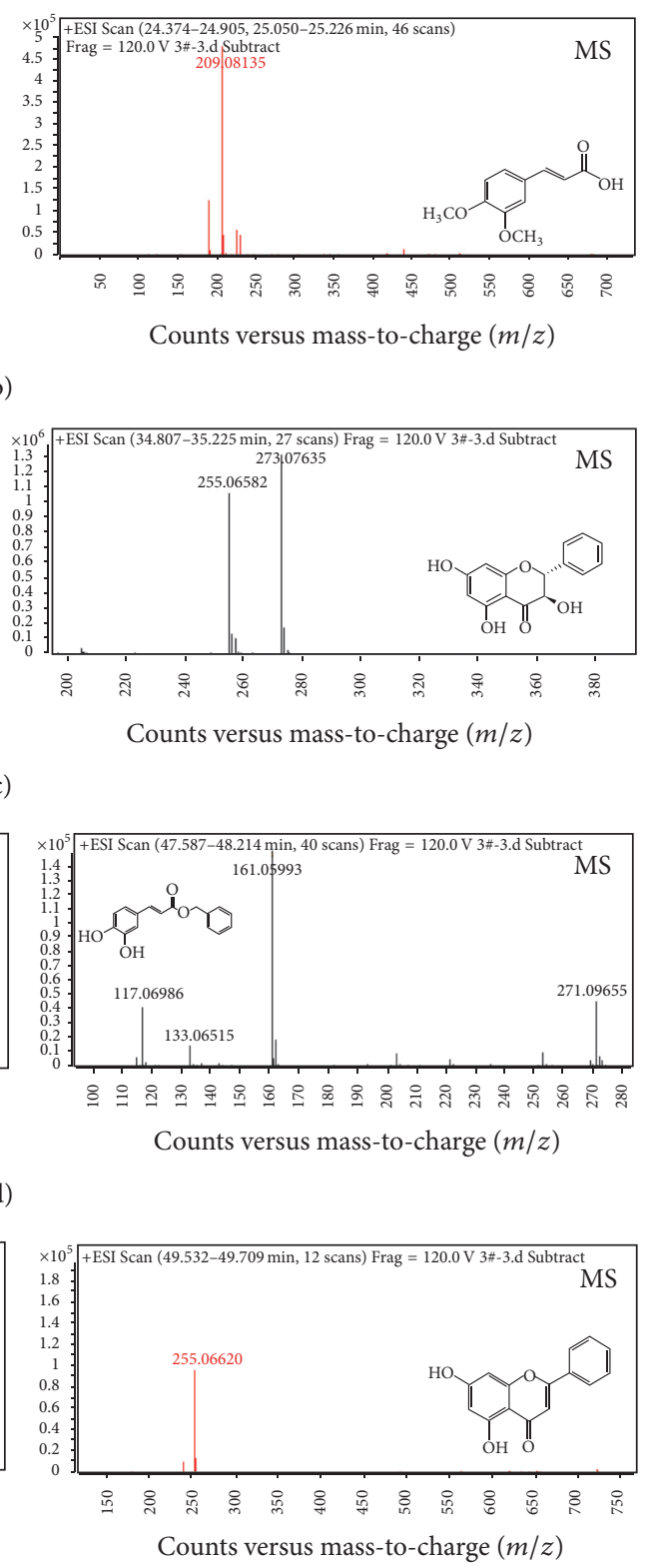

(e)

Figure 3: Continued. 

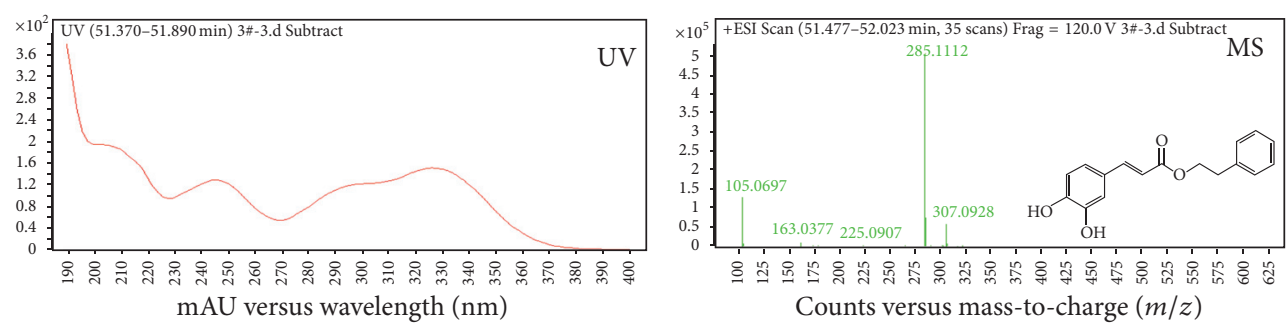

(f)
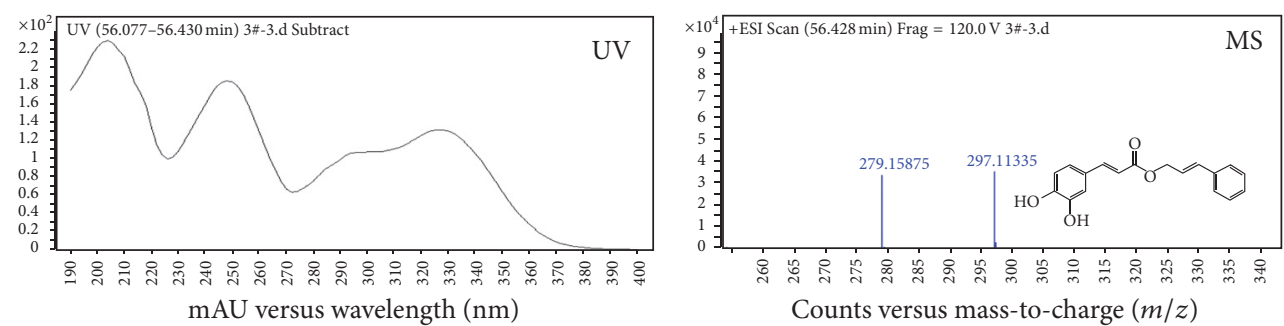

(g)

FIgURE 3: Active compounds isolation and characterization of CP extracts responsible for its cardioprotective activities. (a) HPLC chromatogram of CP fraction 3. Peaks present are as follows: (1) 3,4-dimethoxycinnamic acid (DMCA); (2) pinobanksin; (3) benzyl caffeate (BZC); (4) chrysin; (5) caffeic acid phenethyl ester (CAPE); and (6) cinnamyl caffeate (CNC). Their UV (left) and MS profiles (left) are shown individually as (b) DMCA; (c) pinobanksin; (d) BZC; (e) chrysin; (f) CAPE; (g) CNC.

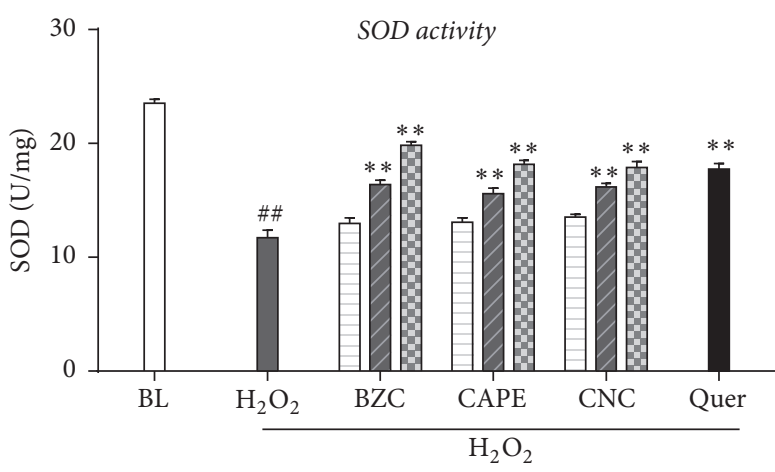

$\square 1 \mu \mathrm{M}$

EDID $10 \mu \mathrm{M}$

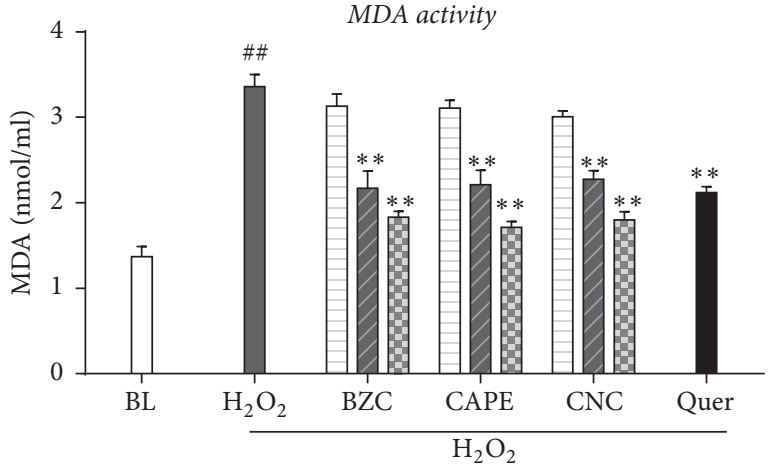

EDI $10 \mu \mathrm{M}$

(a)

(b)

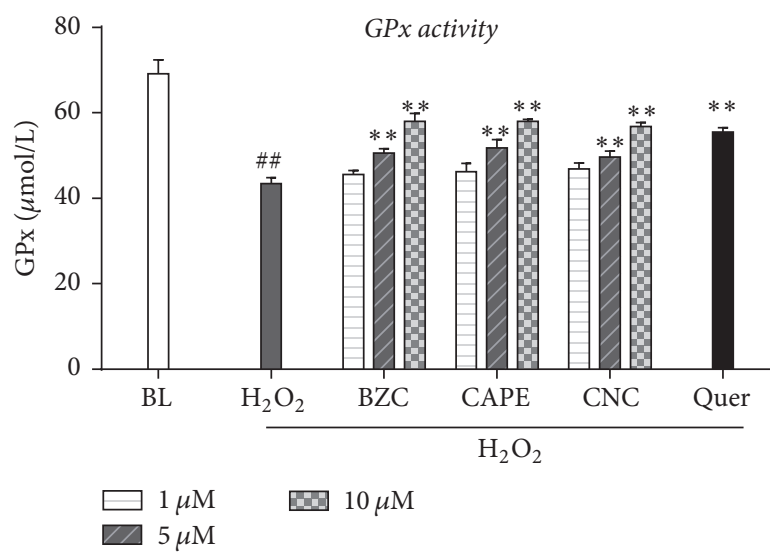

(c)

FIgURE 4: Caffeate derivatives in CP increased cellular antioxidant activities in H9c2 cardiomyocytes. Effects of CP bioactive compounds (BZC, CAPE, and CNC) on cellular SOD (a), MDA, and GPx activities in $\mathrm{H}_{2} \mathrm{O}_{2}$ induced injured H9c2 cardiomyocytes. CP bioactive compounds $(1,5$, and $10 \mu \mathrm{M})$ were pretreated for $12 \mathrm{~h}$ before $6 \mathrm{~h} \mathrm{H}_{2} \mathrm{O}_{2}(700 \mu \mathrm{M})$ insult. ${ }^{* *} P<0.01$ versus oxidative injury group and ${ }^{\# \#} P<0.01$ versus control group. 


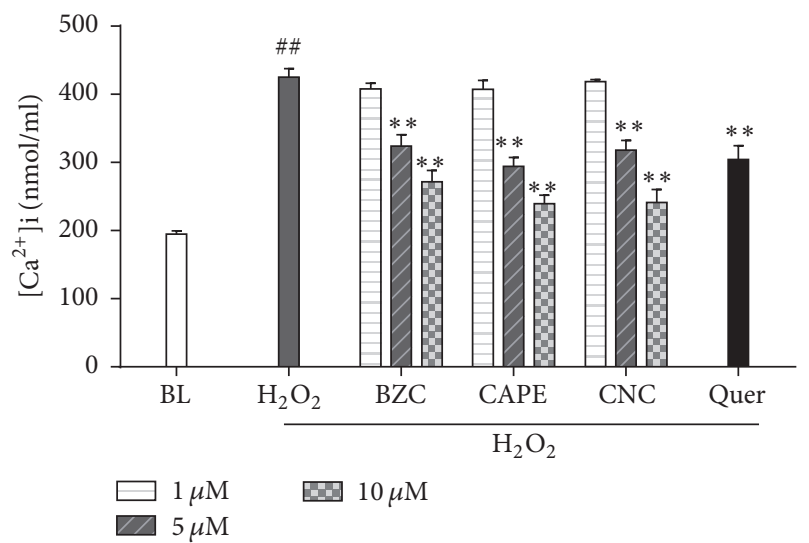

(a)

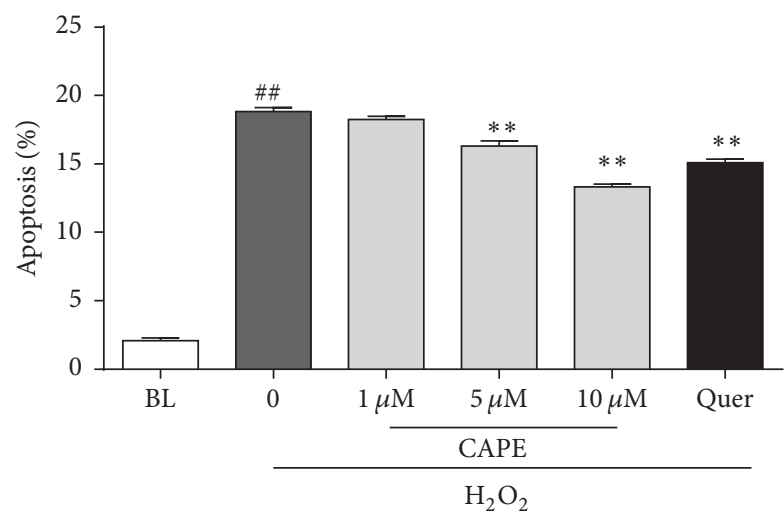

(c)

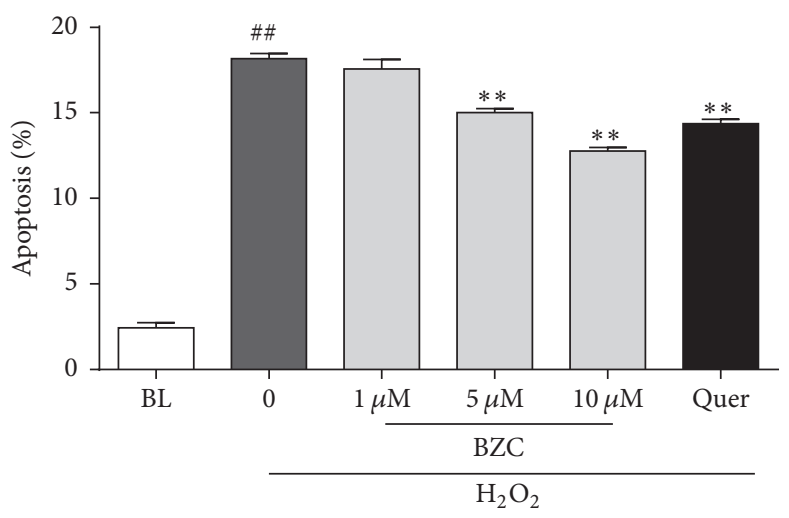

(b)

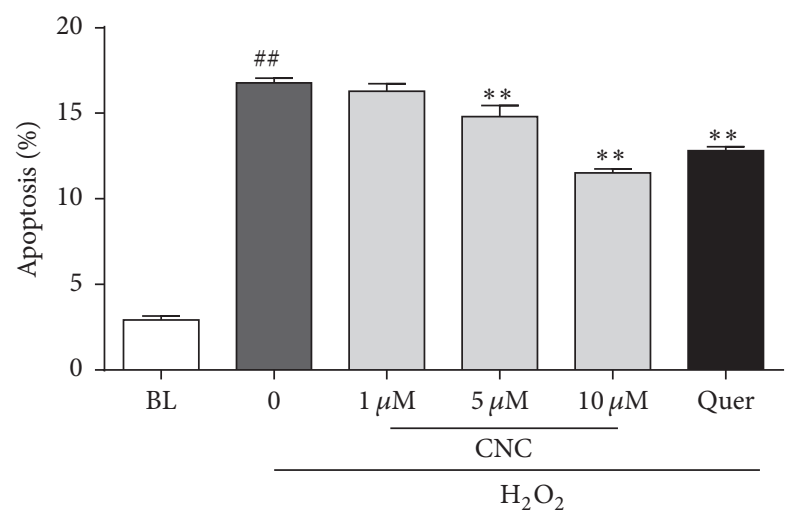

(d)

Figure 5: Caffeate derivatives in $\mathrm{CP}$ decreased the $\mathrm{H}_{2} \mathrm{O}_{2}$ induced elevation of $\left[\mathrm{Ca}^{2+}\right]_{\mathrm{i}}$ and inhibited cell apoptosis in $\mathrm{H} 9 \mathrm{c} 2$ cardiomyocytes. (a) Effects of CP bioactive compounds (BZC, CAPE, and CNC) on intracellular $\left[\mathrm{Ca}^{2+}\right]_{\mathrm{i}}$ induced by $\mathrm{H}_{2} \mathrm{O}_{2}$. $\mathrm{H} 9 \mathrm{c} 2$ cells were pretreated with BZC, CAPE, and CNC for $12 \mathrm{~h}$ and then stimulated with $6 \mathrm{~h} \mathrm{H}_{2} \mathrm{O}_{2}(700 \mu \mathrm{M})$. $\left[\mathrm{Ca}^{2+}\right]_{\mathrm{i}}$ was measured as described in materials and methods. (b-d) Effects of CP bioactive compounds on cell apoptosis induced by $\mathrm{H}_{2} \mathrm{O}_{2}$. Various concentrations (1, 5, and $\left.10 \mu \mathrm{M}\right)$ of BZC (b), CAPE (c), and $\mathrm{CNC}(\mathrm{d})$ were added into cell medium for $12 \mathrm{~h}$ and then stimulated with $6 \mathrm{~h} \mathrm{H}_{2} \mathrm{O}_{2}(700 \mu \mathrm{M})$. Cell apoptotis were analysed using FCM as described in Materials and Methods. ${ }^{* *} P<0.01$ versus oxidative injury group and ${ }^{\# \#} P<0.01$ versus control group.

lower apoptotic cells were observed in caffeate derivatives pretreated cells $(5$ and $10 \mu \mathrm{M})$. Based on these results, we demonstrated that caffeates from $\mathrm{CP}$ could reduce the myocardial injury by inhibiting $\mathrm{H}_{2} \mathrm{O}_{2}$-induced cell apoptosis and restored cytosolic $\left[\mathrm{Ca}^{2+}\right]_{i}$ pool.

\section{Conclusion}

In summary, our study provides an important basis for the use of Chinese propolis for the prevention and treatment of cardiovascular diseases. The crude Chinese propolis extract as well as its isolated compounds caffeate derivatives (CAPE, BZC, and CNC) could mostly possibly be useful for the development of new antimyocardial ischemia drugs, depending on their in vitro activity. However, further in vivo pharmacological and toxicity studies are necessary for its potential clinical usages.

\section{Competing Interests}

All the authors declare that they have no conflict of interests.

\section{Authors' Contributions}

Liping Sun and Xiang Xu conceived and designed the experiments; Liping Sun, Xiang Xu and Miaomiao Ge performed the experiments; Kai Wang and Yifan Chen analyzed the data; Liping Sun, Xiang Xu, and Miaomiao Ge contributed to the reagents/materials/analysis tools; Liping Sun, Kai Wang, Yifan Chen, and Fuliang Hu wrote the paper.

\section{Acknowledgments}

This research was supported partly by grants from the Agricultural Science and Technology Innovation Program (no. CAAS-ASTIP-2016-IAR) and the National Natural Science Foundation of China (no. 31272509).

\section{References}

[1] A. S. Savchenko, J. I. Borissoff, K. Martinod et al., "VWFmediated leukocyte recruitment with chromatin decondensation by PAD 4 increases myocardial ischemia/reperfusion injury in mice," Blood, vol. 123, no. 1, pp. 141-148, 2014. 
[2] F. K. Swirski and M. Nahrendorf, "Leukocyte behavior in atherosclerosis, myocardial infarction, and heart failure," Science, vol. 339, no. 6116, pp. 161-166, 2013.

[3] E. G. Nabel and E. Braunwald, "A tale of coronary artery disease and myocardial infarction," The New England Journal of Medicine, vol. 366, no. 1, pp. 54-63, 2012.

[4] D. Fraccarollo, P. Galuppo, J. Neuser, J. Bauersachs, and J. D. Widder, "Pentaerythritol tetranitrate targeting myocardial reactive oxygen species production improves left ventricular remodeling and function in rats with ischemic heart failure," Hypertension, vol. 66, no. 5, pp. 978-987, 2015.

[5] V. Braunersreuther and V. Jaquet, "Reactive oxygen species in myocardial reperfusion injury: from physiopathology to therapeutic approaches," Current Pharmaceutical Biotechnology, vol. 13, no. 1, pp. 97-114, 2012.

[6] K. Wang, S. Ping, S. Huang et al., "Molecular mechanisms underlying the in vitro anti-inflammatory effects of a flavonoidrich ethanol extract from Chinese propolis (poplar type)," Evidence-Based Complementary and Alternative Medicine, vol. 2013, Article ID 127672, 11 pages, 2013.

[7] J. M. Sforcin and V. Bankova, "Propolis: is there a potential for the development of new drugs?" Journal of Ethnopharmacology, vol. 133, no. 2, pp. 253-260, 2011.

[8] K. Wang, J. Zhang, S. Ping et al., "Anti-inflammatory effects of ethanol extracts of Chinese propolis and buds from poplar (Populus $\times$ canadensis)," Journal of Ethnopharmacology, vol. 155, no. 1, pp. 300-311, 2014.

[9] J. B. Daleprane and D. S. Abdalla, "Emerging roles of propolis: Antioxidant, cardioprotective, and antiangiogenic actions," Evidence-Based Complementary and Alternative Medicine, vol. 2013, Article ID 175135, 8 pages, 2013.

[10] K. Wang, L. Hu, X.-L. Jin et al., "Polyphenol-rich propolis extracts from China and Brazil exert anti-inflammatory effects by modulating ubiquitination of TRAF6 during the activation of NF- $\kappa$ B," Journal of Functional Foods, vol. 19, pp. 464-478, 2015.

[11] Z. Fang, B. Lu, M. Liu et al., "Evaluating the pharmacological mechanism of Chinese medicine Si-Wu-Tang through multilevel data integration," PLoS ONE, vol. 8, no. 11, Article ID e72334, 2013.

[12] S.-R. Hsieh, W.-C. Cheng, Y.-M. Su, C.-H. Chiu, and Y.-M. Liou, "Molecular targets for anti-oxidative protection of green tea polyphenols against myocardial ischemic injury," BioMedicine, vol. 4, no. 4, pp. 7-16, 2014.

[13] D.-A. Chou, Y.-H. Kuo, M.-S. Jan et al., "Caffeate derivatives induce apoptosis in COLO 205 human colorectal carcinoma cells through Fas- and mitochondria-mediated pathways," Food Chemistry, vol. 131, no. 4, pp. 1460-1465, 2012.

[14] J. H. Ha, H. S. Noh, I. W. Shin, J. R. Hahm, and D. R. Kim, "Mitigation of $\mathrm{H} 2 \mathrm{O} 2$-induced autophagic cell death by propofol in H9c2 cardiomyocytes," Cell Biology and Toxicology, vol. 28, no. 1, pp. 19-29, 2012.

[15] K. Wang, X. Jin, Y. Chen et al., "Polyphenol-rich propolis extracts strengthen intestinal barrier function by activating AMPK and ERK signaling," Nutrients, vol. 8, article 272, 2016.

[16] S. Umadevi, V. Gopi, S. P. Simna, A. Parthasarathy, S. M. J. Yousuf, and V. Elangovan, "Studies on the cardio protective role of gallic acid against age-induced cell proliferation and oxidative stress in H9C2 (2-1) cells," Cardiovascular Toxicology, vol. 12, no. 4, pp. 304-311, 2012.
[17] S. M. Nadtochiy and E. K. Redman, "Mediterranean diet and cardioprotection: the role of nitrite, polyunsaturated fatty acids, and polyphenols," Nutrition, vol. 27, no. 7-8, pp. 733-744, 2011.

[18] H. Kaiserová, T. Šimůnek, W. J. F. van der Vijgh, A. Bast, and E. Kvasničková, "Flavonoids as protectors against doxorubicin cardiotoxicity: role of iron chelation, antioxidant activity and inhibition of carbonyl reductase," Biochimica et Biophysica Acta-Molecular Basis of Disease, vol. 1772, no. 9, pp. 1065-1074, 2007.

[19] J. Zhou, Y. Li, J. Zhao, X. Xue, L. Wu, and F. Chen, "Geographical traceability of propolis by high-performance liquidchromatography fingerprints," Food Chemistry, vol. 108, no. 2, pp. 749-759, 2008.

[20] J. Daubney, P. L. Bonner, A. J. Hargreaves, and J. M. Dickenson, "Cardioprotective and cardiotoxic effects of quercetin and two of its in vivo metabolites on differentiated H9c2 cardiomyocytes," Basic and Clinical Pharmacology and Toxicology, vol. 116, no. 2, pp. 96-109, 2015.

[21] C. Angeloni, J. P. E. Spencer, E. Leoncini, P. L. Biagi, and S. Hrelia, "Role of quercetin and its in vivo metabolites in protecting H9c2 cells against oxidative stress," Biochimie, vol. 89, no. 1, pp. 73-82, 2007.

[22] Z. Shouqin, X. Jun, and W. Changzheng, "High hydrostatic pressure extraction of flavonoids from propolis," Journal of Chemical Technology and Biotechnology, vol. 80, no. 1, pp. 5054, 2005.

[23] A. H. Banskota, T. Nagaoka, L. Y. Sumioka et al., "Antiproliferative activity of the Netherlands propolis and its active principles in cancer cell lines," Journal of Ethnopharmacology, vol. 80, no. 1, pp. 67-73, 2002.

[24] T. Usia, A. H. Banskota, Y. Tezuka, K. Midorikawa, K. Matsushige, and S. Kadota, "Constituents of Chinese propolis and their antiproliferative activities," Journal of Natural Products, vol. 65, no. 5, pp. 673-676, 2002.

[25] H. Yang, Y. Dong, H. Du, H. Shi, Y. Peng, and X. Li, "Antioxidant compounds from propolis collected in Anhui, China," Molecules, vol. 16, no. 4, pp. 3444-3455, 2011.

[26] R. Yamauchi, K. Kato, S. Oida et al., "Benzyl caffeate, an antioxidative compound isolated from propolis," Bioscience, Biotechnology, and Biochemistry, vol. 56, no. 8, pp. 1321-1322, 1992.

[27] S. Kumazawa, K. Hayashi, K. Kajiya, T. Ishii, T. Hamasaka, and T. Nakayama, "Studies of the constituents of Uruguayan propolis," Journal of Agricultural and Food Chemistry, vol. 50, no. 17, pp. 4777-4782, 2002.

[28] E. M. Mantawy, W. M. El-Bakly, A. Esmat, A. M. Badr, and E. ElDemerdash, "Chrysin alleviates acute doxorubicin cardiotoxicity in rats via suppression of oxidative stress, inflammation and apoptosis," European Journal of Pharmacology, vol. 728, no. 1, pp. 107-118, 2014.

[29] R. Chang, Y. Li, X. Yang et al., "Protective role of deoxyschizandrin and schisantherin a against myocardial ischemia-reperfusion injury in rats," PLoS ONE, vol. 8, no. 4, Article ID e61590, 2013.

[30] R. C. Chen, G. B. Sun, J. Wang, H. J. Zhang, and X. B. Sun, "Naringin protects against anoxia/reoxygenation-induced apoptosis in $\mathrm{H} 9 \mathrm{c} 2$ cells via the Nrf2 signaling pathway," Food and Function, vol. 6, no. 4, pp. 1331-1344, 2015.

[31] J. J. Lemasters, T. P. Theruvath, Z. Zhong, and A.-L. Nieminen, "Mitochondrial calcium and the permeability transition in cell death," Biochimica et Biophysica Acta-Bioenergetics, vol. 1787, no. 11, pp. 1395-1401, 2009. 
[32] D. M. Ansley and B. Wang, "Oxidative stress and myocardial injury in the diabetic heart," Journal of Pathology, vol. 229, no. 2, pp. 232-241, 2013.

[33] M. Kamil Burgazli, N. Aydogdu, A. Rafiq, M. Mericliler, R. Chasan, and A. Erdogan, "Effects of caffeic acid phenethyl ester (CAPE) on membrane potential and intracellular calcium in human endothelial cells," European Review for Medical and Pharmacological Sciences, vol. 17, no. 6, pp. 720-728, 2013.

[34] O. Ilkun and S. Boudina, "Cardiac dysfunction and oxidative stress in the metabolic syndrome: an update on antioxidant therapies," Current Pharmaceutical Design, vol. 19, no. 27, pp. 4806-4817, 2013.

[35] Y. Lee and Å. B. Gustafsson, "Role of apoptosis in cardiovascular disease," Apoptosis, vol. 14, no. 4, pp. 536-548, 2009. 


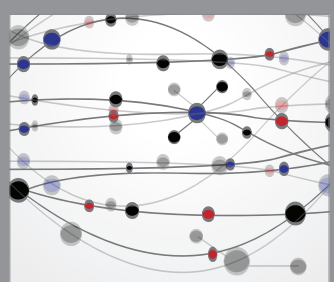

The Scientific World Journal
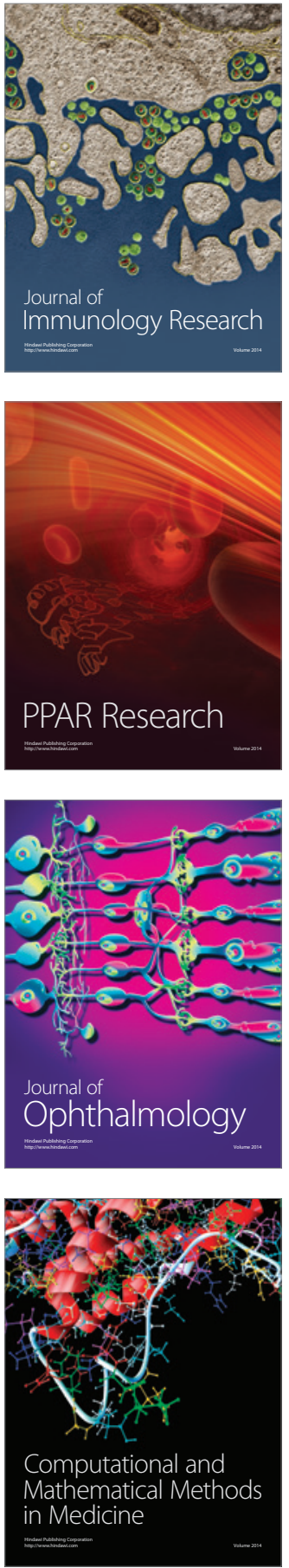

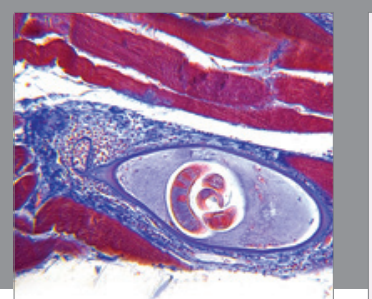

Gastroenterology Research and Practice
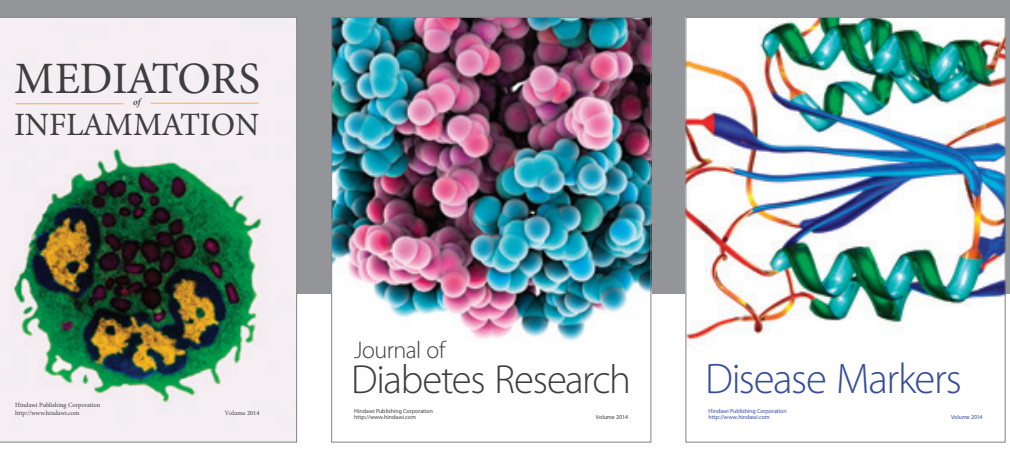

Disease Markers

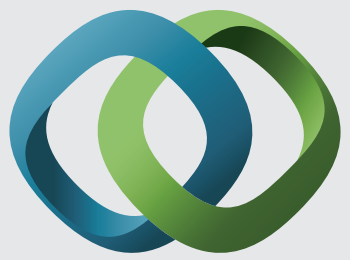

\section{Hindawi}

Submit your manuscripts at

https://www.hindawi.com
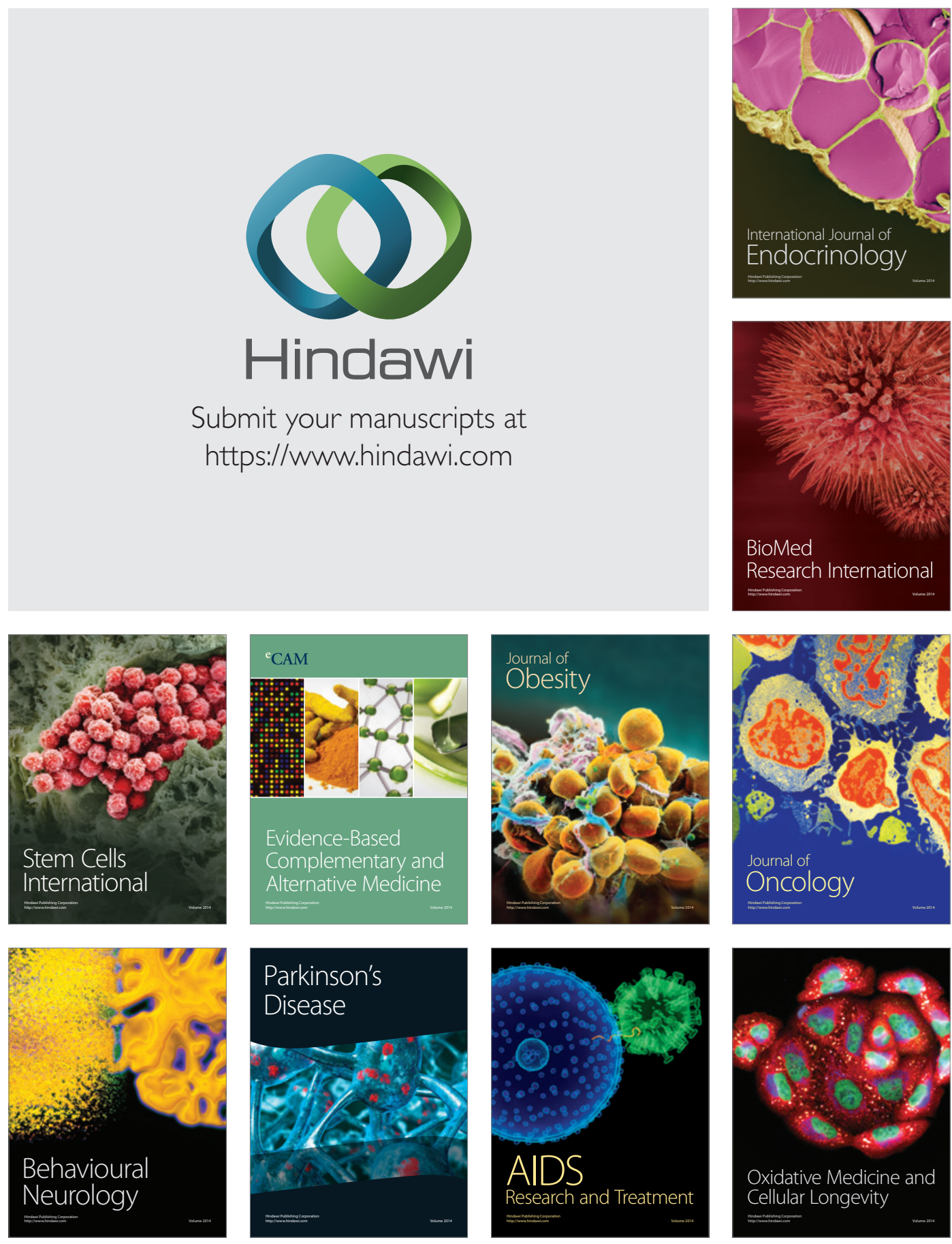